\title{
Comparison among Mechanical Properties of Investment-Cast c.p. Ti, Ti-6Al-7Nb and Ti-15Mo-1Bi Alloys
}

\author{
Chia-Wei Lin*1, Chien-Ping Ju and Jiin-Huey Chern Lin*2 \\ Department of Materials Science and Engineering, National Cheng-Kung University, 70101 Tainan Taiwan, R.O. China
}

The present study compares castability and mechanical performance among alloys of c.p. Ti, Ti-6Al-7Nb and a newly-developed Ti-15Mo-1Bi in regard to their as-cast state. Experimental results indicate that average cast length of Ti-6Al-7Nb appears a little lower than c.p. $\mathrm{Ti}$ and Ti-15Mo-1Bi, although the differences are not significant. C.p. Ti has an hcp $\alpha$ phase of lath-type morphology with serrated, irregular grain boundaries. Ti-6Al-7Nb is dominated by hexagonal $\alpha^{\prime}$ phase with acicular martensitic morphology. In particular, Ti-15Mo-1Bi is comprised of equiaxed, metastable bcc $\beta$ phase. The hardened layer thicknesses of three materials are similar. Ti-15Mo-1Bi has the highest surface microvickers hardness, while c.p. Ti has the lowest. The bulk hardness of c.p. Ti is much lower than the other two alloys which display similar hardness. Notably, Ti-15Mo-1Bi and Ti-6Al-7Nb have similar bending strength which is far higher than c.p. Ti. The bending modulus of Ti-15Mo-1Bi is significantly lower than c.p. Ti and Ti-6Al-7Nb. Ti-15Mo-1Bi also shows a much larger elastic recovery angle than two other materials. Tensile test indicates that Ti-15Mo-1Bi has a similar UTS but much higher YS and elongation along with much lower tensile modulus compared to Ti-6Al-7Nb.

(Received June 15, 2004; Accepted August 2, 2004)

Keywords: titanium alloy, investment casting, microstructure, mechanical properties

\section{Introduction}

Commercially pure titanium (c.p. Ti) has established a reputation of low density, high corrosion resistance and excellent biocompatibility for dental prosthetic applications including crown and bridge, partial framework, dental implant, etc. ${ }^{1-3)}$ Though titanium is highly reactive with both oxygen and molding materials at high temperatures, further developments in casting machines and molding materials have been proven to be capable of assuring the clinical use of titanium dental castings. ${ }^{4-6)}$

Despite its many good properties, some disadvantages (especially relatively low strength) of cast pure titanium have often been criticized to be insufficient for certain dental applications such as long-spanned fixed prostheses and the frameworks of removable partial dentures (RPD). ${ }^{4,7-10)} \mathrm{Ti}-$ $6 \mathrm{Al}-7 \mathrm{Nb}$ alloy was originally developed using niobium to replace vanadium in $\mathrm{Ti}-6 \mathrm{Al}-4 \mathrm{~V}$ for orthopedic applications. ${ }^{11)}$ Then, this alloy has also been used as a dental casting metal, especially in Japan. Kobayashi et al. ${ }^{12)}$ showed that Ti-6Al-7Nb alloy exhibited sufficient castability, suitable mechanical properties and excellent corrosion resistance for dental application. At this writing, Ti-15Mo alloy has come to be known as having a bcc structure with a good combination of strength, modulus and elongation. ${ }^{13)}$ Also, the addition of bismuth was reported to be very effective in lowering the surface tension (surface energy) of molten titanium and improving castability. ${ }^{14)}$

This work compares castability and mechanical performance among c.p. Ti, Ti-6Al-7Nb and our newly-developed Ti-15Mo-1Bi alloy in terms of their as-cast state. Specifically, the microstructure, phase constituents, bending and tensile behavior, along with castability of the three materials are investigated and compared.

\footnotetext{
${ }^{* 1}$ Graduate Student, National Cheng-Kung University

*2Corresponding author, E-mail: chernlin9@yahoo.com, National ChengKung University
}

\section{Experimental Methods}

The materials used for this study are to be characterized as c.p. Ti, Ti-6Al-7Nb and Ti-15Mo-1Bi alloys (Note: all compositions in this study are presented by weight). All materials were prepared from raw materials including titanium (99.8\% in purity), molybdenum (99.95\% in purity), niobium (99.8\% in purity), aluminum (99.95\% in purity) and bismuth $(99.5 \%$ in purity) using a commercial arc-melting vacuum-pressure type casting system (Castmatic, Iwatani Corp., Japan). Prior to melting/casting, the melting chamber was evacuated and purged with argon. An argon pressure of 1.5 Pa was maintained during melting. Appropriate amounts of various metals were melted in a U-shaped copper hearth with a tungsten electrode. The ingot was turned upside-down and re-melted three times to improve chemical homogeneity. Just before casting, the ingot was melted again in an openbased copper hearth under an argon pressure of $1.5 \mathrm{~Pa}$. The difference in pressure between the two chambers allowed the molten alloy to instantly drop into a mold composed of magnesia-based investment material heated to $473 \mathrm{~K}$. A scanning electron microscopy (SEM)-energy dispersive spectroscopy (EDS) analysis indicates that chemical compositions of two cast alloys (Ti-5.9Al-7.0Nb and Ti-14.9Mo$1.2 \mathrm{Bi}$, respectively) were quite close to those designed.

To serve various purposes for this study, three different kinds of wax patterns were used for casting, i.e., (1) six needle-shaped patterns, $0.45 \mathrm{~mm}$ dia. nylon lines (Fig. 1) for the evaluation of castability; (2) slab-shaped $(36 \mathrm{~mm} \times$ $5 \mathrm{~mm} \times 1.5 \mathrm{~mm}$ ) patterns for metallographic examination, $\mathrm{X}$-ray diffraction (XRD), three-point bending and hardness tests; and (3) patterns for tensile test with a gage length of $10 \mathrm{~mm}$ and rectangular cross section of $3 \mathrm{~mm} \times 1.5 \mathrm{~mm}$. Castability of these different materials was evaluated by their cast lengths. As for data analysis one-way ANOVA followed by Student-Newman-Kuels test was used to evaluate statistical significance of the data. In all cases the statistical differences were considered significant at $\mathrm{p}<0.05$. 

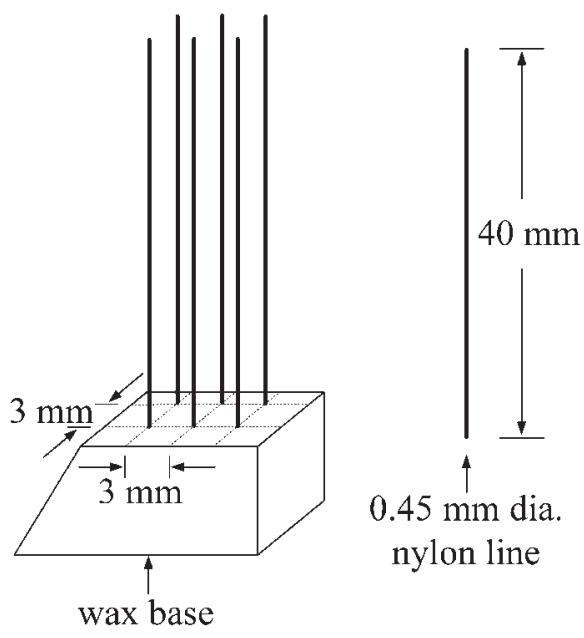

Fig. 1 Specification of nylon pattern used for castability evaluation.

XRD for phase analysis was conducted using a Rigaku diffractometer (Rigaku D-max IIIV, Rigaku Co., Tokyo, Japan) operated at $30 \mathrm{kV}$ and $20 \mathrm{~mA}$ with a scanning speed of $1^{\circ} / \mathrm{min}$. A Ni-filtered $\mathrm{CuK} \alpha$ radiation was used for the study. A silicon standard was used for calibrating diffraction angles with various phases being identified by matching each characteristic peak in the diffraction patterns using JCPDS files. Surfaces of the cast alloys for microstructural study were mechanically polished via a standard metallographic procedure to a final level of $0.05 \mu \mathrm{m}$ alumina powder, followed by etching in a Kroll's reagent comprising water, nitric acid, and hydrofluoric acid (80:15:5 in volume). Microstructure of the etched alloys was examined using an optical microscope (Leitz Labrorlux 12 Pols, Leica Co., Germany).

Three-point bending tests were performed using a desk-top mechanical tester (Shimadzu AGS-500D, Tokyo, Japan) operated at a crosshead speed of $0.5 \mathrm{~mm} / \mathrm{s}$. The bending strength was determined using the equation, $\sigma=$ $\left.3 P L / 2 b h^{2},{ }^{15}\right)$ where $\sigma$ is the bending strength $(\mathrm{MPa}) ; P$ is the load $(\mathrm{kg}), L$ is the span length $(\mathrm{mm}), b$ is the specimen width $(\mathrm{mm})$, and $h$ is the specimen thickness $(\mathrm{mm})$. The modulus of elasticity in bending was calculated from the load increment and corresponding deflection increment between the two points on a straight line as far apart as possible using the equation, $E=L^{3} \Delta P / 4 b h^{3} \Delta \delta$, where $E$ is the modulus of elasticity in bending $(\mathrm{Pa}), \Delta P$ is the load increment measured from preload $(\mathrm{N})$, and $\Delta \delta$ is the deflection increment at midspan measured from preload. The average bending strength and modulus of elasticity were taken from five tests under each condition. The elastic recovery (springback) capability for each material was evaluated based on the changes in deflection angle when loading was removed.

A servo-hydraulic type testing machine (EHF-EG, Shimadzu Co., Tokyo, Japan) was used for tensile test. Tensile testing was performed at room temperature at a constant crosshead speed of $8.33 \times 10^{-6} \mathrm{~m} / \mathrm{s}$. Average ultimate tensile strength (UTS), yield strength (YS) at $0.2 \%$ offset, modulus of elasticity and elongation to failure were taken from five tests under each condition. Hardness of the samples was evaluated using a Matsuzawa MXT70 micro-
Table 1 Cast lengths of investigated materials.

\begin{tabular}{cc}
\hline Material & Cast length $(\mathrm{mm})$ \\
\hline c.p. $\mathrm{Ti}$ & $27.0 \pm 4.9$ \\
Ti-6Al-7Nb & $25.7 \pm 2.9$ \\
Ti-15Mo-1Bi & $28.4 \pm 4.1$ \\
\hline
\end{tabular}

vickers hardness tester with a load of $0.2 \mathrm{~kg}$ for 15 seconds. To determine the variation in hardness with sample depth, the microvickers hardness tests were performed on the crosssections of castings.

\section{Results and Discussion}

Cast lengths (a measure of castability) of c.p. Ti, Ti-6Al$7 \mathrm{Nb}$ and $\mathrm{Ti}-15 \mathrm{Mo}-1 \mathrm{Bi}$ are compared in Table 1 . As indicated in the table, the average cast length of Ti-6Al-7Nb $(25.7 \mathrm{~mm})$ appears a little lower than those of c.p. Ti $(27.0 \mathrm{~mm})$ and Ti$15 \mathrm{Mo}-1 \mathrm{Bi}(28.4 \mathrm{~mm})$, despite the fact that the differences are not significant. The little difference in "mold-filling index" (a measure of castability) between pure $\mathrm{Ti}$ and $\mathrm{Ti}-6 \mathrm{Al}-7 \mathrm{Nb}$ alloy was also indicated by Shimizu et al. ${ }^{16)}$

Many factors have been considered to affect the castability of a metal including mold design, mold temperature, cooling rate, molten metal temperature, surface tension, mold reaction, dendrite formation, etc. ${ }^{17)}$ Since all process parameters (power level, heating duration, mold size, shape and temperature, etc.) were fixed in the study, the factors that affect castability most likely were material-related factors such as mold reaction, surface tension and dendrite formation. Ragone et al. ${ }^{18)}$ indicated that the addition of an alloy element to a pure metal always lowers the fluidity (increasing viscosity) of the metal due to the formation of dendrites that causes resistance to proceed fluid flow in the early stage of solidification. From this point of view, the dendrite factor could not be fitted in to explain the high castability of the proposed Ti-15 Mo-1Bi alloy. Rather, in an earlier study, Cheng et al. ${ }^{14)}$ showed that the addition of bismuth could lower the surface tension (surface energy) of titanium and significantly improve castability. The present study suggests that surface tension reduction caused by $\mathrm{Bi}$-inducement may have a dominant effect in maintaining high castability of the alloy.

Titanium alloys may be categorized into different types according to their room temperature phases. ${ }^{19)}$ In this research work, aluminum is an $\alpha$-stabilizer, while molybdenum and niobium are intended as $\beta$-isomorphous stabilizers. According to the binary $\mathrm{Ti}-\mathrm{Bi}$ phase diagram, $\mathrm{Bi}$ is a $\beta$ eutectoid element. The XRD patterns and morphologies of three investigated materials are shown in Figs. 2 and 3, respectively. It can be seen that the as-cast c.p. Ti has an $\alpha$ phase with hcp crystal structure. Figure 3(a) shows that this c.p. Ti has lath-type morphology with serrated, irregular grain boundaries, indicating a rapid cooling process during casting. ${ }^{13)}$

The as-cast Ti-6Al-7Nb alloy was dominated by hexagonal $\alpha^{\prime}$ phase with a distorted hep crystal structure. ${ }^{20)}$ As shown in Fig. 3(b), Ti-6Al-7Nb has an acicular martensitic morphology with high-temperature $\beta$-phase grain boundaries barely 


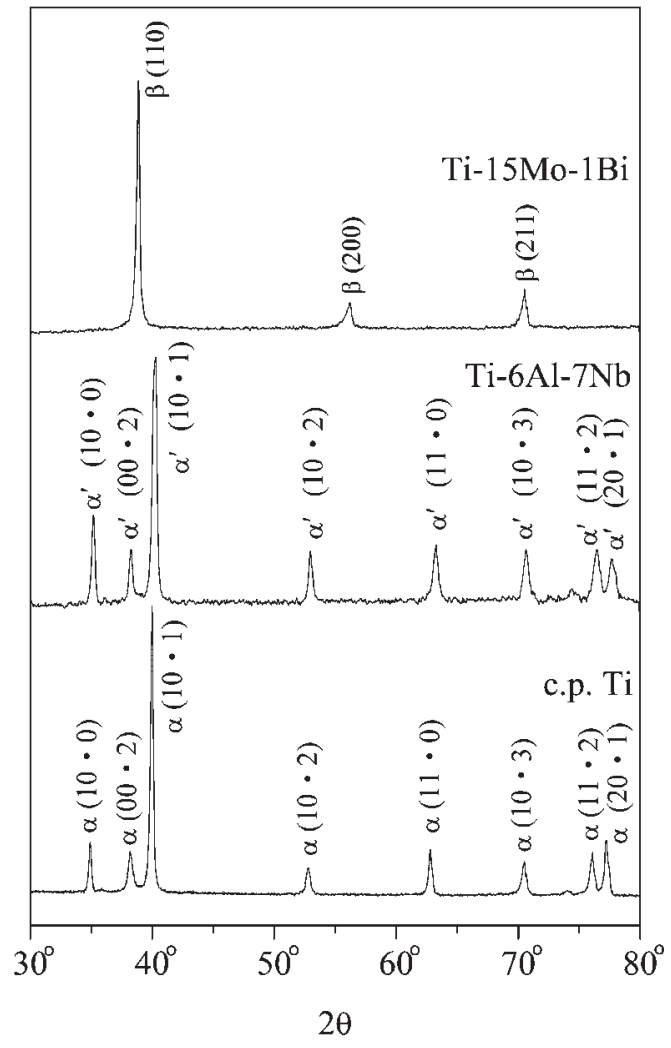

Fig. 2 XRD patterns of investigated materials.

visible. This acicular martensitic morphology is similar to that observed by Ahmed and Rack, who claimed that a high cooling rate is required for Ti-6Al-4V to attain a martensitic morphology. ${ }^{20)}$ According to Filip et al. ${ }^{21)}$ a completely martensitic structure could be obtained at a cooling rate $>18 \mathrm{~K} / \mathrm{s}$. This suggests that the cooling rate for the proposed casting process should be at least as high as $18 \mathrm{~K} / \mathrm{s}$.

The as-cast Ti-15Mo-1Bi alloy was comprised primarily of equiaxed, metastable $\beta$ phase with bcc crystal structure (Fig. 3(c)). The retention of $\beta$ phase at higher Mo contents is consistent with both the early result reported by Davis et al. ${ }^{22)}$ and the more recent result of Bania. ${ }^{23)}$ Bania reported that a minimum of 10 mass $\%$ Mo was needed in a Ti-Mo alloy to

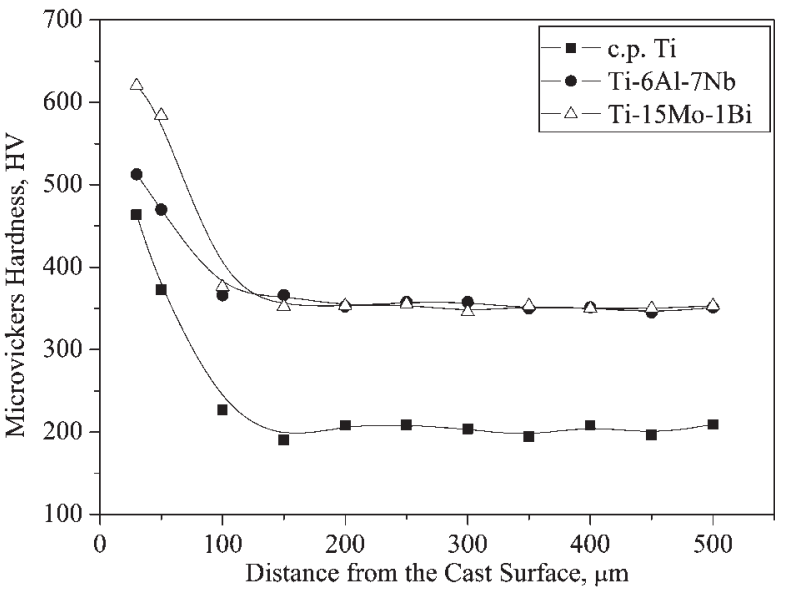

Fig. 4 Cross-sectional microvickers hardness of investigated materials.

fully stabilize $\beta$ phase at room temperature.

Variations in microvickers hardness with depth from the surfaces of castings are demonstrated in Fig. 4. As can be seen from the graph, Ti-15Mo-1Bi depicts the highest surface hardness, while c.p. Ti is the lowest. The hardened layer ( $\alpha$ case) thickness appears to be roughly $100-150 \mu \mathrm{m}$ for all three materials. Although the microvickers hardness values in the interior (bulk) of Ti-15Mo-1Bi and Ti-6Al-7Nb are similar (about $350 \mathrm{HV}$ ), the surface hardness of Ti-15Mo-1Bi is significantly higher than that of Ti-6Al-7Nb probably due to their different degrees in reaction with mold material. In addition, the bulk microvickers hardness of c.p. Ti is much lower (about 200 HV). The hardened layer, that is almost unavoidable in investment-cast $\mathrm{Ti}$ and Ti-alloys, forms through the decomposition of the investment oxides and diffusion of the resulting elements into the casting. ${ }^{24,25)}$ Although the measurements were straightforward, the interpretation of the data are complex. Such effects as solution and/or precipitation hardening, grain size and crystal structure/phase would all affect the hardness of the alloy. The primary cause to the relatively high surface hardness of Ti-15Mo-1Bi might be its stronger reaction with investment material during casting. A much higher bulk hardness level of Ti-15Mo-1Bi and Ti-6Al-7Nb (than c.p. Ti) is probably due
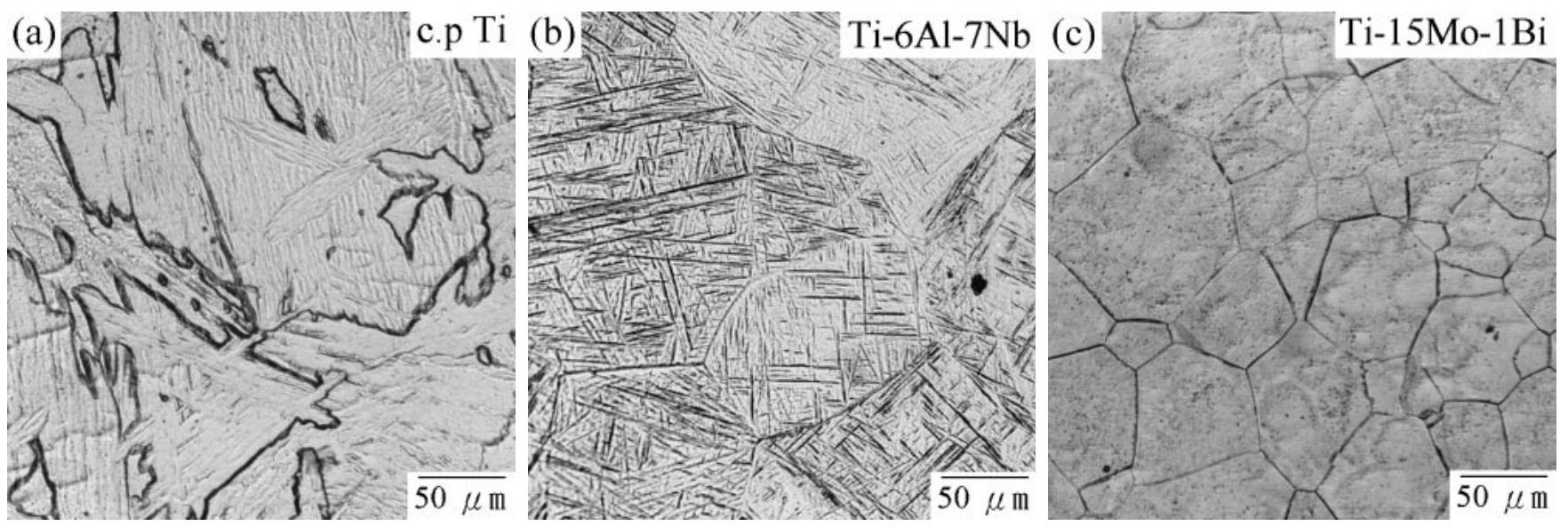

Fig. 3 Optical micrographs of investigated materials. 
Table 2 Bending test data of investigated materials.

\begin{tabular}{cccc}
\hline Material & $\begin{array}{c}\text { Bending strength } \\
(\mathrm{MPa})\end{array}$ & $\begin{array}{c}\text { Bending modulus } \\
(\mathrm{GPa})\end{array}$ & $\begin{array}{c}\text { Elastic recovery angle } \\
(\text { degree })\end{array}$ \\
\hline c.p. Ti & $925 \pm 21$ & $104 \pm 4$ & $7.7 \pm 0.2$ \\
Ti-6Al-7Nb & $1943 \pm 26$ & $111 \pm 3$ & $22.0 \pm 0.4$ \\
Ti-15Mo-1Bi & $1975 \pm 38$ & $90 \pm 1$ & $27.3 \pm 1.2$ \\
\hline
\end{tabular}

Table 3 Tensile test data of investigated materials.

\begin{tabular}{cccr}
\hline Material & $\begin{array}{c}\text { Yielding strength } \\
(\mathrm{MPa})\end{array}$ & $\begin{array}{c}\text { Tensile strength } \\
(\mathrm{MPa})\end{array}$ & \multicolumn{2}{c}{$\begin{array}{c}\text { Tensile modulus } \\
(\mathrm{GPa})\end{array}$} & $\begin{array}{c}\text { Elongation } \\
(\%)\end{array}$ \\
\hline c.p. Ti & $429 \pm 20$ & $544 \pm 21$ & $105 \pm 8$ \\
Ti-6Al-7Nb & $824 \pm 18$ & $1045 \pm 17$ & $126 \pm 8$ \\
Ti-15Mo-1Bi & $953 \pm 34$ & $1013 \pm 29$ & $3.7 \pm 0.8$ \\
\hline
\end{tabular}

to a combined effect of solution hardening and their much finer morphology.

Bending properties of three cast materials are listed in Table 2. As indicated in the table, cast Ti-15Mo-1Bi and Ti6Al-7Nb alloys have similar bending strengths (1975 and $1943 \mathrm{MPa}$, respectively), which were far higher than that of cast c.p. Ti (925 MPa). The bending modulus of Ti-15Mo$1 \mathrm{Bi}(90 \mathrm{GPa})$, however, is significantly lower than those of Ti-6Al-7Nb (111 GPa) and c.p. Ti (105 GPa). One way ANOVA statistical analysis indicated that the differences are significant. Kobayashi et al. ${ }^{12)}$ suggested that the greater strength of Ti-6Al-7Nb alloy than c.p. Ti was due to a combined effect of solution strengthening and structurerefining strengthening. Same effect is suggested to account for the higher strengths of the proposed Ti-15Mo-1Bi and Ti6Al-7Nb alloys as compared with c.p. Ti. The lower bending modulus of Ti-15Mo-1Bi as opposed to the other two materials arising from a direct result of the presence of $\beta$ phase in the alloy. ${ }^{13)}$

The relatively high strength and low modulus of Ti-15Mo$1 \mathrm{Bi}$ lead to an elastic recovery angle which are larger than Ti$6 \mathrm{Al}-7 \mathrm{Nb}$ by almost one-quarter and larger than c.p. Ti by as much as 2.5 times. High elastic recovery capability is an indication of high strength and low modulus and is essential for many load-bearing implant and dental applications. It is also worth noting that during bending all $\mathrm{Ti}-15 \mathrm{Mo}-1 \mathrm{Bi}$ and c.p. Ti samples had reached the pre-set deflection limit of $8 \mathrm{~mm}$ without failure. However, about $40 \%$ of all Ti-6Al-7Nb samples failed prior to reaching the pre-set limit, indicating a lower ductility level of the material. The lower ductility of Ti-6Al-7Nb than c.p. Ti and Ti-15Mo was also observed by Niinomi. ${ }^{26)}$

The favorable mechanical performance of Ti-15Mo-1Bi was again confirmed in tensile tests. As indicated in Table 3, Ti-15Mo-1Bi and Ti-6Al-7Nb alloys have far higher strengths and lower elongations than c.p. Ti. Comparison between the two alloys indicates that Ti-15Mo-1Bi has a similar UTS (1013 MPa) but much higher YS (953 MPa) and much lower tensile modulus (98 GPa) than those of Ti-Al$7 \mathrm{Nb}$ (1045 MPa, 824 MPa and $126 \mathrm{GPa}$, respectively). This much larger elongation of Ti-15Mo-1Bi $(7.8 \%)$ than Ti-6Al$7 \mathrm{Nb}(3.7 \%)$ again displays the better ductility of Ti-15Mo$1 \mathrm{Bi}$.
For a material to be used as a medical implant, an increase in material strength yet maintaining a low modulus is advantageous, since a low modulus material is generally favored for implant application for its reduced stressshielding effect. ${ }^{27)}$ From this point of view, Ti-15Mo-1Bi demonstrates a greater potential than the other two materials. Even with a large elongation value, the elastic recovery angle of c.p. Ti is still much lower than the other two materials due to its low strength. Practically, a larger elastic recovery angle means an increased adjustability without fear of breakage for a device (e.g., clasp for RPD). The higher ductility and the elastic recovery angle of $\mathrm{Ti}-15 \mathrm{Mo}-1 \mathrm{Bi}$ also indicate its superiority to the other two materials.

\section{Conclusions}

The castability, bending and tensile properties of c.p. Ti, Ti-6Al-7Nb and Ti-15Mo-1Bi alloys were investigated. Obtained results are as follows.

(1) The average cast length of Ti-6Al-7Nb is a little bit lower than that of c.p. Ti and Ti-15Mo-1Bi, although the differences are not significant.

(2) C.p. Ti has a hcp $\alpha$ phase of lath-type morphology with serrated, irregular grain boundaries. Ti-6Al-7Nb was dominated by hexagonal $\alpha^{\prime}$ phase with acicular martensitic morphology. Ti-15Mo-1Bi was comprised of equiaxed, metastable bcc $\beta$ phase.

(3) The hardened layer ( $\alpha$ case) thicknesses of three materials were similar. Ti-15Mo-1Bi had the highest surface microvickers hardness, while c.p. Ti was the lowest. The bulk hardness of c.p. Ti was much lower than the other two alloys that had similar hardness.

(4) Ti-15Mo-1Bi and Ti-6Al-7Nb had similar bending strengths which are far higher than c.p. Ti. The bending modulus of Ti-15Mo-1Bi was significantly lower than c.p. Ti and Ti-6Al-7Nb. Ti-15Mo-1Bi showed a much larger elastic recovery angle than the other two materials.

(5) Ti-15Mo-1Bi has a similar UTS but having much higher YS and elongation as well as much lower tensile modulus than $\mathrm{Ti}-\mathrm{Al}-7 \mathrm{Nb}$. 


\section{REFERENCES}

1) E. P. Lautenschlager and P. Monaghan: Int. Dent. J. 43 (1993) $245-$ 253.

2) H. Nakajima and T. Okabe: Dent. Mater. J. 15 (1996) 77-90.

3) M. Koike and H. Fujii: Biomaterials 22 (2001) 2931-2936.

4) T. Okabe and H. Herø: Cell. Mater. 5 (1995) 211-230.

5) K. Ida, T. Togaya, S. Tsutsumi and M. Takeuchi: Dent. Mater. J. 1 (1982) 8-21.

6) H. Hamanaka, H. Doi, T. Yoneyama and O. Okuno: J. Dent. Res. 68 (1989) 1529-1533.

7) T. Kawazoe and K. Suese: J. Dent. Med. 30 (1989) 317-328.

8) A. Kuroiwa and Y. Igarashi: J. Jpn. Prosthodont Soc. 42 (1998) $547-$ 558

9) K. Watanabe, O. Miyakawa, Y. Takada, O. Okuno and T. Okabe: Biomaterials 24 (2003) 1737-1743.

10) J. Zhu, A. Kamiya, T. Yamada, W. Shi and K. Naganuma: Mater. Sci. Eng. A339 (2003) 53-62.

11) M. Semlitsch, F. Stabu and H. Weber: Biomed. Tech. 30 (1985) 334 339

12) E. Kobayashi, T. J. Wang, H. Doi, T. Yoneyama and H. Hamanaka: J. Mater. Sci. Mater. Med. 9 (1998) 567-574.

13) W. F. Ho, C. P. Ju and J. H. Chern Lin: Biomaterials 20 (1999) 2115 2122.

14) W. W. Cheng, J. H. Chern Lin and C. P. Ju: AFS. Trans. 01-169 (2001)
987-996.

15) A. Guha: Metals Handbook, 9th ed., 8 (ASM International, Metals Park, OH, 1985) pp. 133.

16) H. Shimizu, T. Habu, Y. Takada, K. Watanabe, O. Okuno and T. Okabe: Biomaterials 23 (2002) 2275-2281.

17) L. F. Porter and P. C. Rosenthal: AFS Trans. 60 (1952) 725-739.

18) D. V. Ragone, C. M. Adams and H. F. Taylor: AFS Trans. 64 (1956) 640-653.

19) E. W. Collings: The physical metallurgy of titanium alloys, (ASM International, Metals Park, OH, 1984) pp. 5-11.

20) T. Ahmed and H. J. Rack: Mater. Sci. Eng. A243 (1998) 206-211.

21) R. Filip, K. Kubiak, W. Ziaja, J. Sieniawski: J. Mater. Process. Technol. 133 (2003) 84-89.

22) R. Davis, H. M. Flower and D. R. F. West: J. Mater. Sci. 14 (1979) 712722.

23) P. J. Bania: Beta titanium alloys in the 1990's, ed. by D. Eylon, R. R. Boyer and D. A. Koss, (TMS, Warrendale, PA, 1993) pp. 3-14.

24) M. Kikuchi, Y. Takada, S. Kiyosue, M. Yoda, M. Woldu, Z. Cai, O. Okuno and T. Okabe: Dent. Mater. 19 (2003) 174-181.

25) O. Miyakawa, K. Watanabe, S. Okawa, S. Nakano, M. Kobayashi and N. Shiokawa: Dent. Mater. J. 8 (1989) 175-185.

26) M. Niinomi: Mater. Sci. Eng. A243 (1998) 231-236.

27) D. R. Sumner and J. O. Galante: Clin. Orthop. Relat. Res. 274 (1992) 202-212. 